Tropical Journal of Pharmaceutical Research December 2010; 9 (6): 557-564

(C) Pharmacotherapy Group, Faculty of Pharmacy, University of Benin,

Benin City, 300001 Nigeria.

All rights reserved.

Research Article

Available online at http://www.tjpr.org

\title{
Availability and Expiry of Essential Medicines and Supplies During the 'Pull' and 'Push' Drug Acquisition Systems in a Rural Ugandan Hospital
}

\author{
Yona Tumwine ${ }^{1}$, Paul Kutyabami ${ }^{1}$, Richard A Odoi ${ }^{1}$ and Joan \\ N Kalyango ${ }^{1,2^{\star}}$ \\ ${ }^{1}$ Department of Pharmacy, ${ }^{2}$ Clinical Epidemiology Unit, College of Health Sciences, Makerere University, Kampala, \\ Uganda
}

\begin{abstract}
Purpose: To assess the impact of the 'Pull' system on the availability and reduction of expiry of essential medicines and medical supplies and to determine factors affecting their availability in Kilembe Hospital, Uganda.

Methods: Records of 27 essential medicines and 11 medical supplies were reviewed over two-year periods in the Push (2000 - 2001) and Pull system (2004 - 2005). Key informant interviews were conducted. The data were analyzed using STATA version 8. Comparison of availability was effected using Wilcoxon signed rank tests.

Results: The median number of days out-of-stock for drugs and medical supplies was 94 versus 24 ( $p<$ $0.001)$ and 8 versus $0(p<0.39)$ for the Push and Pull systems, respectively. The mean percentage days out-of-stock in the two periods was $15.3 \%$ versus $3.5 \%(p<0.001)$ and $1.8 \%$ versus $1.3 \%(p=$ 0.34) for drugs and medical supplies, respectively. Expired drugs were worth USD 1584 (25 items) in 2000/2001 and USD 1307 (13 items) in 2004/2005. Factors contributing to availability of supplies were inadequate training, lack of transport and inadequate funding.

Conclusion: The Pull system improved availability of essential medicines and reduced the volume of expiries. Availability of funds, transport, staff training and supervision should be addressed for maximal benefits.
\end{abstract}

Key words: Push system, Pull system, Availability of medicines, Medicines expiry 


\section{INTRODUCTION}

Availability of medicines is important as far as the reduction of mortality and morbidity associated with disease burden are concerned. However, lack of essential medicines is still one of the most serious public health problems. About $30 \%$ of the world's population lacks the medicines they need. The situation is worse in the poorest parts of Africa and Asia where the figure rises to over $50 \%$ [1].

The essential medicines concept introduced in 1977 went a long way in improving availability of drugs [2,3]. Availability was further enhanced with the kit system which was designed to guarantee that certain subsets of medicines essential for primary health care delivery were available at service delivery points. Although these kits were originally meant to be supplemented by other drugs as needed, in many areas they became the main, and at times, the sole drug supplies. This constituted the 'Push' system of drug supply. The authorized supplier determined the types and quantities of drugs to be issued to the peripheral units. It offered several advantages especially in areas affected by wars or natural disasters but there remained some inconsistency between the needs of the user areas and the drugs supplied [4].

A review of drug management and procurement in Uganda revealed that although there was fairly regular supply of kits, there were frequent drug stock-outs in many health units. In addition, large quantities of expired drugs and medical supplies were found in most district level facilities. This was attributed to poor quantification practices and to donors ordering large quantities of drugs without proper co-ordination with the recipient departments [5]. Expired medicines stock is clearly a waste of resources which cannot be afforded in a resource-constrained nation [6]. The Ministry of Health of Uganda introduced the 'Pull' system of drug supply in the year
2003 in an effort to overcome the problems of drug availability and expiries. This system requires the health units to determine the types and quantities of medicines and medical supplies they need $[7,8]$.

However, this system has not been evaluated to determine if it has achieved the objectives for which it was set up. Drugs and supplies, being expensive commodities, need to be utilized optimally to avoid wastage. Furthermore, it is important that patients access the necessary medicines in order to control the disease burden. Availability of necessary drugs also helps to promote rational drug use. This study was conducted to: assess the performance of the Pull system in improving the availability and reduction of expiry of essential drugs and medical supplies, assess the level of monitoring and supervision of the implementation of the pull system, and determine other factors affecting availability of drugs and medical supplies in Kilembe Hospital which is located in Kilembe town in Uganda.

\section{METHODS}

A cross-sectional study with quantitative and qualitative methods of data collection was conducted in December 2006 and January 2007 at Kilembe Hospital in Kasese district in the south western part of Uganda, about 500 kilometers from Kampala, the capital city of Uganda. It has a bed capacity for 150 patients and serves a population of approximately 153,300 people. The hospital is run through a joint venture involving the government of Uganda and the Catholic Church. The study was approved by the Faculty of Medicine Research and Ethics Committee of Makerere University and permission was also given by Kilembe Hospital administration.

Various records were reviewed over a 2-year period during the Push system (2000 - 2001) and another 2-year period during the Pull system (2004 - 2005). Quantitative data were collected using data extraction forms. 
Qualitative data were collected using key informant interviews which were directed by a topic guide. The topics discussed with the key informants include: factors affecting availability of drugs, methods of drug quantification used, the drug ordering system and support supervision by the district. The interviews involved a moderator and another person taking notes. The participants for the key informant interviews were: the hospital administrator, two staff members working in stores section, the officer in-charge of the pharmacy department and one other pharmacy staff, the senior nursing officer, one records' assistant, and one medical officer. Many of the staff members had worked at the hospital during the Pull and Push systems.

Availability of essential drugs was assessed as the number of out-of-stock drugs and the number of days over which selected essential drugs were out of stock over a two-year period (counted at 365 days per year). The volume of expired drugs, percentage of planned monitoring and supervision visits that were implemented and some aspects of stock management, e.g., availability and correct use of stock cards, and storage practices were also evaluated. In addition, other factors such as lead time from placement of orders to receipt of goods, availability of transport, percentage of health workers trained in needs assessment, availability of human resource, availability of funds, and availability of drugs at the supplier points were assessed as possible determinants of availability of drugs and supplies. A total of 27 essential drugs from the Essential drug list of Uganda and 11 medical supplies were used as indicator drugs and supplies.

\section{Data analysis}

The quantitative data were entered into Microsoft Excel and exported to STATA version 8 (Stata, College Station, TX, USA) for statistical analysis. The data were summarized using descriptive statistics, e.g., mean, median with standard deviation, and minimum and maximum values. The Wilcoxon signed rank test was used to test for differences in number and percentage of days out of stock over the two periods. The percentage number of drugs that went out of stock over the two periods was compared using the McNemar test. Comparisons were made for ever going out of stock and going out of stock for more than 30 days. Differences were considered to be statistically significant if the $p$-value was less than 0.05. The qualitative data were transcribed verbatim from taped recordings and analyzed manually by separation into emerging themes.

\section{RESULTS}

The median number of days out of stock for drugs and medical supplies was higher in the Push system compared to the Pull system (94 versus 24 days and 8 versus 0 , respectively). However, the difference in the median days for the medical supplies in the two periods was not significantly different. In addition, the average percentage days out-ofstock for drugs and medical supplies were higher in the Push system compared to the Pull system (15.3\% versus $3.5 \%$ and $1.8 \%$ versus $1.3 \%$, respectively). The difference in average percentage days out-of-stock for medical supplies was not significantly different. The percentage number of drugs and medical supplies out-of-stock in 2000 2001 period was also higher than in 2004 2005 period $(77.8 \%$ versus $66.7 \%$ and 72.7 $\%$ versus $36.4 \%$, respectively). These differences were not statistically significant. However when comparisons were made for percentage number of drugs out-of-stock for more than 30 days, the difference for drugs was statistically significant while that for supplies was not different. In addition, there was higher volume and number of expired drugs and medical supplies in the 2001 2002 period compared to the $2004-2005$ period. However, according to the report of the supplies officer, most of the drugs that expired in the Pull system were purchased 
Table 1: Comparison of availability and expiries of drugs and medical supplies in the Push and Pull systems

\begin{tabular}{|c|c|c|c|c|}
\hline Item & 2001-2 & 2003-4 & $\begin{array}{c}\text { Difference } \\
(95 \% \mathrm{Cl})\end{array}$ & $p$-value \\
\hline Median days out of stock for drugs (Min, Max) & $94(0,385)$ & $24(0,96)$ & & $<0.001^{*}$ \\
\hline $\begin{array}{l}\text { Average } \% \text { days out-of-stock for drugs } \\
\% \text { no. of drugs out-of-stock } \\
\% \text { no. of druas out-of-stock for }>30 \text { davs }\end{array}$ & $\begin{array}{l}15.3 \\
77.8 \\
77.8\end{array}$ & $\begin{array}{l}3.5 \\
66.7 \\
40.7\end{array}$ & $\begin{array}{l}11.8(6.6-12.8) \\
11.1(-8-30.0) \\
37.0(15.1-59.0)\end{array}$ & $\begin{array}{l}<0.001^{*} \\
0.38 \\
0.002^{*}\end{array}$ \\
\hline $\begin{array}{l}\% \text { no. of drugs out-of-stock for }>30 \text { days } \\
\text { Median days out of stock for medical supplies } \\
\text { (Min, Max) }\end{array}$ & $8(0,38)$ & $0(0,54)$ & & $0.002^{n}$ \\
\hline $\begin{array}{l}\text { Average \% days out-of-stock for medical } \\
\text { supplies }\end{array}$ & 1.8 & 1.3 & $0.5(-1.5-2.7)$ & 0.34 \\
\hline $\begin{array}{l}\% \text { no. of medical supplies out-of-stock } \\
\% \text { no. of medical supplies out-of-stock for > }\end{array}$ & 72.7 & 36.4 & $36.4(-1.1-73.9)$ & 0.13 \\
\hline 30 days & 18.2 & 18.2 & $0.0(-44.7-44.7)$ & 1.00 \\
\hline $\begin{array}{l}\text { Amount worth of expired drugs in US dollars } \\
\text { Number of expired drugs }\end{array}$ & $\begin{array}{l}1584 \\
25\end{array}$ & $\begin{array}{l}1307 \\
13\end{array}$ & & \\
\hline
\end{tabular}

under the Push system. The results are summarized in Table 1.

Quinine tablets had the highest percentage stock-out in the Push system followed by ciprofloxacin (52.7 and $42.9 \%$, respecttively). On the other hand, diclofenac injection had the highest percentage stockout in the Pull system followed by ferrous sulphate tablets (14.8 and $11.8 \%$, respectively). Among medical supplies, cotton wool had the highest percentage stock-out in the Push system while cannulas had the highest percentage stock out in the Pull system (5.2 and $7.4 \%$, respectively). The results of unavailability of the different drugs and medical supplies are summarized in Tables 2 and 3.

Other factors that the key informants felt were affecting the availability of drugs were the low levels of staffing and lack of training in the system of procurement. "Very few people including myself and one pharmacy staff were trained in drug quantification and the Pull system of procurement. We were supposed to train other staff but because of the heavy workload due to having low number of staff, we have never managed to train others" reported one key informant.
Lack of transport was also identified as a hindrance to drug availability. "Joint Medical Stores which is our main supplier does not provide transport like the National Medical Stores used to during the Push system. The hospital has only got one small omnibus necessitating bigger orders to be supplied in installments. This leads to delays in receiving some drugs and also increases the transportation costs" reported one key informant.

Lack of funds to purchase drugs also affected their availability. "Sometimes the funds available on our credit lines are not sufficient and the orders have to be reconciled with the available money. We end up purchasing less drugs than we need" reported another key informant.

The key informants felt that abrupt changes of policies may also cause expiry of drugs. "There are sometimes abrupt changes in policies, for example, the changes in antimalarial policy whereby the first line drugs were changed from chloroquine and Fansidar to artemether-lumefantrine yet there were already large supplies of the former. These could lead to expiry of the drugs in stock" reported a key informant.

"At times large quantities of drugs with short expiry dates are received using the Push 
Tumwine et al

Table 2: Availability of specific drugs in the Push and Pull system

\begin{tabular}{|c|c|c|c|c|}
\hline Item & $\begin{array}{l}\text { Days out-of- } \\
\text { stock } \\
2000-2001\end{array}$ & $\begin{array}{l}\begin{array}{l}\% \text { out-of- } \\
\text { stock }\end{array} \\
2000-2001\end{array}$ & $\begin{array}{l}\text { Days out-of- } \\
\text { stock } \\
2004-2005\end{array}$ & $\begin{array}{l}\% \text { out-of-stock } \\
2004-2005\end{array}$ \\
\hline Amoxycillin capsules & 124 & 17.0 & 30 & 4.1 \\
\hline Benzathine injection & 0 & 0 & 0 & 0 \\
\hline Benzylpenicillin & 147 & 20.1 & 39 & 5.3 \\
\hline Chloroquine injection & 93 & 12.7 & 23 & 3.2 \\
\hline Chloroquine tablets & 0 & 0 & 0 & 0 \\
\hline Ciprofloxacin tablets & 313 & 42.9 & 36 & 4.9 \\
\hline Cotrimoxazole tablets & 98 & 13.4 & 0 & 0 \\
\hline Diazepam injection & 138 & 18.9 & 0 & 0 \\
\hline Diazepam rectal & 59 & 8.1 & 37 & 5.1 \\
\hline Diclofenac injection & 252 & 34.5 & 96 & 13.2 \\
\hline Diclofenac tablets & 64 & 8.8 & 70 & 9.6 \\
\hline Ferrous tablets & 120 & 16.4 & 40 & 5.5 \\
\hline Folic acid tablets & 94 & 12.9 & 64 & 8.8 \\
\hline $\begin{array}{l}\text { Gentamycin injection } \\
\text { Hydrocortisone }\end{array}$ & 115 & 15.8 & 33 & 4.5 \\
\hline injection & 263 & 36.0 & 35 & 4.8 \\
\hline Ketamine injection & 119 & 16.3 & 71 & 9.7 \\
\hline Lignocaine injection & 192 & 26.3 & 0 & 0 \\
\hline Mebendazole tablets & 0 & 0 & 0 & 0 \\
\hline $\begin{array}{l}\text { Methylergometrine } \\
\text { injection }\end{array}$ & 91 & & 17 & 23 \\
\hline $\begin{array}{l}\text { Inection } \\
\text { Metronidazole tablets }\end{array}$ & 111 & $\begin{array}{l}12.0 \\
15.2\end{array}$ & 10 & $\begin{array}{l}2.0 \\
1.4\end{array}$ \\
\hline ORS & 59 & 8.1 & 30 & 4.1 \\
\hline Paracetamol tablets & 0 & 0 & 0 & 0 \\
\hline PPF injection & 0 & 0 & 0 & 0 \\
\hline Quinine injection & 385 & 52.7 & 24 & 3.3 \\
\hline Quinine tablets & 65 & 8.9 & 31 & 4.2 \\
\hline $\mathrm{SP}^{\star}$ & 64 & 8.8 & 0 & 0 \\
\hline Vitamin A & 0 & 0 & 10 & 1.4 \\
\hline
\end{tabular}

Table 1: Availability of specific medical supplies in the Push and Pull systems

\begin{tabular}{lcccc}
\hline Supply & $\begin{array}{c}\text { Days out- } \\
\text { of-stock } \\
\mathbf{2 0 0 0 - 2 0 0 1}\end{array}$ & $\begin{array}{c}\text { \% out-of- } \\
\text { stock 2000- } \\
\mathbf{2 0 0 1}\end{array}$ & $\begin{array}{c}\text { Days out- } \\
\text { of-stock } \\
\mathbf{2 0 0 4 - 2 0 0 5}\end{array}$ & $\begin{array}{c}\text { \% out-of- } \\
\text { stock 2004- } \\
\mathbf{2 0 0 5}\end{array}$ \\
\hline Cannulars G18 & 20 & 2.7 & 0 & 0 \\
Cannulars G20 & 12 & 1.6 & 54 & 7.4 \\
Cannulars G22 & 7 & 1.0 & 36 & 4.9 \\
Cotton wool & 38 & 5.2 & 9 & 1.2 \\
Gauze & 24 & 3.3 & 0 & 0 \\
Infusion sets & 7 & 1.0 & 0 & 0 \\
Needles/Syringes 2mls & 0 & 0 & 0 & 0 \\
Needles/Syringes 5mls & 0 & 0 & 0 & 0 \\
Plaster adhesive & 8 & 1.1 & 0 & 0 \\
Surgical blades G20 & 32 & 4.4 & 4 & 0.5 \\
Surgical gloves & 0 & 0.0 & 0 & 0 \\
\hline
\end{tabular}


system including Coartem and antiretroviral drugs. This raises the possibility of expiries" reported a key informant.

Estimation of drug needs was usually based on past consumption and rarely on morbidity patterns. It was done on a regular basis by the medical superintendent, supplies officer and the pharmacy in-charge. Drug orders were submitted every two months. The average lead time from submission of orders to receipt of goods was two weeks. When drugs are received, they are stored according to First-In-First-Out (FIFO) and First-ExpiryFirst-Out (FEFO) principles. Stock cards were available and they were well up-dated. Most of the drugs ordered were usually available at the supplier points. Evaluation of the order records made during the Pull system showed that on average $95.7 \%$ of the items ordered during 2004 - 2005 period were supplied.

Although support supervision is one of the strong components of the Pull system, it had not been effectively implemented. Out of the four planned visits by the district, 3 were effected, while out of the four planned inservice visits, only 2 were effected. Some of the key informants attributed the low levels of support supervision to lack of manpower. In addition, not all reports for visits effected were available since in some cases, findings from the monitoring visits were communicated verbally with no documented reports made.

\section{DISCUSSION}

There was generally improved supply of drugs in the Pull system compared to the Push system. The median number of days out of stock in the Push system was almost four times that in the Pull system. In addition, the percentage number of drugs that went out of stock for more than 30 days in the Push system was higher than that in the Pull system. This is possibly because the health units were able to identify their specific needs and aimed at satisfying them as opposed to the Push system where standard items and quantities were sent without determining what the specific need at a particular time was. However since we compared data between two different periods as opposed to comparison of hospitals using the different systems, it is possible that some of the effects seen were due to changes over time. It was not possible to compare hospitals using the different systems because all the hospitals were using the Pull system.

Although, there was a trend towards better availability of medical supplies in the Pull system compared to the Push system, the difference was not statistically significant. The medical (non-drug) supplies had low levels of unavailability in the two periods when compared to drugs. This is possibly because the medical supplies were used during the daily activities of the health workers and thus efforts might have been made to stock them as opposed to drugs which they could ask patients to buy. In addition, the range of drugs was usually higher than that of medical supplies and thus it was harder to maintain all of them in stock at any particular time as opposed to medical supplies that have a narrower range. The Pull system has also been observed to improve availability of medical supplies in Nepal [9].

Non-availability of essential medicines such as quinine for long periods (more than half of the evaluation time) raises concerns about the management of severe malaria. In addition, drugs that may be necessary for resuscitation such as hydrocortisone were out of stock for long periods. This problem would likely have affected the quality of care provided at the health facility.

The volume of expired drugs was also reduced in the Pull system compared to the Push system. The health units were able to order for drugs they need as opposed to the Push system where drugs were supplied irrespective of whether they were needed or not. This was bound to cause expiries. The fact that the health units had a specified amount of credit which they could use to 
obtain medicines helped them to prioritize their needs. It is unlikely that they bought drugs in much larger quantities than they needed which would cause expiries. However, other changes might have taken place that reduced the amount of medicines expiries, e.g., the health units might have improved their drug management systems over time regardless of the system used in obtaining medicines.

Lack of adequate training in medicines quantification was cited as one of the reasons affecting availability. This is probably because staff members were not able to predict how much medicines were needed which might have led to drug shortages. This finding is similar to what was found in a study undertaken in Malawi where lack of training was cited as possibly contributing to unavailability of medicines [10]. The situation in our study was better than that in the study in Malawi where none of the personnel that were involved in drug procurement was trained in drug management as opposed to our study where two personnel at the health facility were trained in drug quantification.

Lack of transport affected availability because the health facility tried to buy quantities of drugs that could be delivered using the available transport. This might have been less than what was required. The hospital is about 500 kilometres from Kampala where the main supplier of medicines for the facility was. This implies that frequent trips could not be made easily with the available transport. Lack of transport has also been cited as a contributing factor to non-availability of drugs in Southern Sudan[11].

Inadequacy of funding was also cited possibly because if the money at the credit lines is not sufficient, there may have to be prioritization which may lead to shortages of some essential medicines. Inadequacy of funding has been cited as a major reason for non-availability of drugs in another study [6].
The degree of supervision was inadequate showing that the implementation of the Pull system was not optimal then. Inadequate supervision was cited as a possible contributing factor to unavailability of drugs in Malawi

\section{Limitation of study}

Our study was limited in not being able to compare the Push and Pull systems concurrently since all health facilities were using the Pull system. It was thus possible that changes over time may have brought about some of the observed differences. However, the improved drug availability and reduced expiry during the Pull system is likely to be due to the system since it was cited that some drugs that are currently being supplied through the Push system, e.g., artemetherlumefantrine and anti-retrovirals still present availability and expiry problems.

\section{CONCLUSION}

The Pull system showed improved drug supply and reduced expiries of drugs. However, there is need to strengthen it further through training of staff dealing in drug supply management, providing support supervision to the health facilities and provision of adequate funding for the supplies.

\section{ACKNOWLEDGEMENT}

The authors acknowledge the administration of Kilembe Hospital for permission to carry out the study in their facility and the staff members for their cooperation. One of the authors is also grateful to his parents, $\mathrm{Mr}$ \& Mrs Tumwine, for funding this study.

\section{REFERENCES}

1. WHO, Equitable access to essential medicines: a framework for collective action., in WHO Policy Perspectives on Medicines. 2004.

2. Quick JD, Essential medicines twenty five years on: closing the access gap. Health policy and planning, 2003. 18(1): p. 1-3. 
3. Laing RB. Waning A, Ford GN, Hoen ET. 25 years of the WHO essential medicines lists: progress and challenges. The Lancet, 2003; 361(9370): 1723-1729.

4. WHO. Studying the pharmaceutical area. . Health action in crises [cited 2010 Feb]; Available from:

http://www.who.int/hac/techguidance/tools/disr upted_sectors/module 11/en/index.html.

5. Muyingo $\bar{S}$, David V, Olupot G, Ekochu E, Sebagenzi E, Kiragga D, and Ngabirano $T$, Baseline assessment of drug logistics systems in twelve DISH - supported districts \& service delivery points (draft report). 2000, Delivery of Improved Services for Health (DISH) Project for United States Agency for International Development. p. 15-34.

6. Foster SD, Improving the supply \& use of essential medicines in Sub-saharan Africa, in Policy Research and External affairs complex Working paper, World bank, Editor. 1990.

7. Uganda Malaria Control Programme Ministry of Health. Uganda Malaria Control Strategic Plan 2005/06 - 2009/10. 2005 [cited 201010 October]; Available from: http://www.eac.int/health/index.php?option=co m_docman\&task=doc_download\&gid=52\&ltem $i d=144$.
8. Ministry of Health (Uganda). Annual Health Sector Performance Report Financial Year 2003/2004. 2004 [cited 2010 Oct]; Available from: http://www.health.go.ug/docs/AHSPR.pdf.

9. USAID. Pull system. Nepal Family health program technical brief \#13 [cited 201014 Mar]; Available from: http://www.jsi.com/NFHP/Docs/TechnicalBriefs 113_pull_system.pdf.

10. Lufesi N, Andrew M, Aursnes I. Deficient supplies of drugs for life threatening diseases in an African community. BMC Health Services Research 2007 Jan 2010 [cited 7 1]; 86]. Available from: http://www.biomedcentral.com/14726963/7/86.

11. John Snow Inc. Sudan: Building Local Capacity to Improve Availability of Medicines for the People of Southern Sudan. [cited 201014 Mar]; Available from: www.jsi.com/.../Sudan_Building_Local_Capacity_to_Improve_Availa bility_of_Medicines_for_the_People_of_South ern_Sudan.cfm 